DOI: 10.33310/2518-7813-2019-66-3-31-36

УДК: 376-611.85:616.7-053.4

\title{
Павел БОчкОВ
}

аспирант кафедры ортопедагогики, реабилитологии и ортопсихологии Национального государственного педагогического университета им. М.П. Драгоманова,

2. Киев, Украина

e-mail: pbochkov@ukr.net

\section{МЕТОДЫ РАЗВИТИЯ И КОРРЕКЦИИ РАВНОВЕСИЯ У ДОШКОЛЬНИКОВ}

\begin{abstract}
В статье систематизированы и проанализированы методы формирования функции равновесия у дошкольников с нарушениями опорно-двигательного аппарата. В основу коррекции динамической устойчивости у данного контингента детей были положены филогенетически обусловленные механизмы постуральной системы апломба, отражённые в периоде раннего онтогенеза ребёнка: вестибулярная - зрительная - проприоцептивная - подарная - окуломоторная. Для совершенствования каждого из этих входных каналов постуральной системы апломба был разработан специфический методический алгоритм развития и коррекции функции равновесия у дошкольников с моторными нарушениями. Для вестибулярного канала предлагается использовать методы гидравлической перевёрнутости (зеркальности), «невесомости», плавности (дозированных угловых ускорений). Для зрительного канала можно использовать методы «тёмной комнаты», «камертона», «рассвета». Совершенствование проприоцептивного канала постуральной системы апломба предполагает применение методов постепенного уменьшения площади опорной поверхности, усиления проприоцептивных ощущений (метод «двух вееров»). Подарный канал вестибулярной системы ребёнка можно развивать посредством следующих методов: «топографического», «двухопорности - одноопорности», сенсорной стимуляции, контрастного метода, а также метода «ходуль». Окуломоторика ребёнка с нарушениями равновесия может быть усовершенствована с помощью метода расширения окуломоторных пространственно-временных возможностей глаз, метода "мячика», а также метода визуального избирательного захвата объекта, вычленения его из множества объектов или быстроменяющейся обстановки. Дана классификация методов с их условным разделением на естественные, филогенетически и онтогенетически предопределённые, и искусственные, основанные на применении предметно-пространственной составляющей (оборудования, тренажёров и инвентаря), а также использующие возможности информационнокомпьютерных технологий с обратной биологической связью.

К перспективам исследования методов развития и коррекции функции равновесия у дошкольников с двигательными нарушениями относится разработка конкретных комплексов упражнений по каждому из разрабатываемых методов с дальнейшей их практической апробацией на данном контингенте детей.

Ключевые слова: методы, равновесие, дошкольники, двигательные нарушения, постуральная система апломба.
\end{abstract}

Развитие и коррекция функции равновесия у дошкольников с нарушениями опорнодвигательного аппарата невозможны без предварительного создания необходимого методического базиса, на основе которого и будет реализовываться разрабатываемая система совершенствования постуральных возможностей данного контингента детей. В ряде исследований в той или иной мере нашли отражение поиски решения данной проблемы [1, 3 - 4, 6 - 7]. Однако нами не было обнаружено системного подхода в разработке методов развития и коррекции функции равновесия у дошкольников с нарушениями опорнодвигательного аппарата применительно к каждому из пяти каналов постуральной системы апломба: вестибулярному - зрительному - проприоцептивному - подарному - окуломоторному. К тому же более тщательной классификации требует применение различных методов развития равновесия с учётом аспектов естественности и искус- ственности их применения. Всё это и предопределило актуальность данной статьи.

Целью настоящего исследования является систематизация существующих методов развития и коррекции функции равновесия у дошкольников с нарушениями опорно-двигательного аппарата и их классификация по отношению к каждому входному каналу постуральной системы апломба.

Начнём с первого внешнего канала постуральной системы апломба - вестибулярного. Вестибулярная система ребёнка в числе первых начинает формироваться уже в утробе матери: плод чаще всего располагается по отношению к опоре вниз головой и у него формируется зеркально-перевёрнутое представление о внешнем мире. К тому же на поздних сроках беременности плод живёт в околоплодных водах довольно активной жизнью: постоянно колышется в них при различных движениях матери и изменении её 
положения в пространстве, поворачивается в разные стороны, разворачивается, кардинальным образом меняет своё положение в матке (например, с головного предлежания - к ножному). Данные онтогенетические особенности формирования первого канала постуральной системы будущего ребёнка предопределяют методы развития и коррекции функции равновесия:

1. Метод гидравлической «перевёрнутости» (зеркальности). Руководствуясь принципом природосообразности, имеет смысл следовать онтогенетической логике формирования вестибулярного аппарата у ребёнка и начинать его тренинги из обратного, перевёрнутого положения. Ведь вначале ребёнок воспринимает потолок как пол, а пол - как потолок. Данный феномен великолепно отражён в известном аттракционе «Дом вверх дном». Даже получасовое пребывание в доме, где всё расположено наоборот, вызывает головокружение, поташнивание и общее ухудшение состояния. Возможно, таким образом себя чувствует новорождённый малыш, на которого буквально «обрушивается» новый мир с его непривычными координатами: то, что довольно долго было верхом, вдруг становится низом. В дальнейшем младенец адаптируется к этим новым условиям существования, но мы не должны забывать о том, что ключом к запуску данного канала постуральной системы апломба является всё-таки первичная «перевёрнутость» мира.

2. Метод «невесомости». Природа распорядилась так, чтобы первые месяцы своего существования и развития плод находился в воде, в облегчённых в гравитационном плане условиях существования. Такое уютное нахождение в воде чем-то напоминает состояние невесомости, поскольку давление на опору в воде, если ребёнок плавает, приближается к нулю. Общеизвестно, что околоплодные воды по своему химическому составу очень похожи на морскую воду и имеют высокую плотность, что повышает действие выталкивающей (архимедовой) силы. На наш взгляд, имеет смысл взять на вооружение метод «невесомости» при развитии и коррекции функции динамической устойчивости у дошкольников - ведь именно с ощущения невесомости начинается знакомство плода с ждущим его после родов внешним миром.

3. Метод плавности (дозированных угловых ускорений). Изначальное нахождение плода в околоплодных (фетальных) водах предопределяет специфику режима его движений и возникающих в полукружных канальцах ускорениях специальной жидкости (эндолимфы). Другими словами, формирование вестибулярного аппарата происходит на фоне медленных раздражений в полукружных канальцах, вызванных относительно плавными ускорениями тела (головы) в водной среде. И лишь переходя после родов к существованию в условиях твёрдой опоры и действующей гравитации ребёнок получает в своих перемещениях и движениях более мощную стимуляцию вестибулярного аппарата.

Теперь остановимся подробней на зрительном канале системы равновесия дошкольника. Следуя онтогенетической логике развития, становится ясно, что во внутриутробном периоде доминировала вестибулярная составляющая постуральной системы апломба. Зрение не включалось в регуляцию положения тела в пространстве и, в каком-то плане, шло вторым темпом за вестибулярными функциями. На наш взгляд, это предопределило возможные методы тренировки внешнего зрительного канала в общей системе равновесия у детей:

1. Метод «тёмной комнаты». Отдавая в онтогенезе пальму первенства при формировании общей функции равновесия ребёнка вестибулярном каналу, на наш взгляд, следует соблюсти данную методическую последовательность и при коррекционных тренингах. Другими словами, развивая зрительный канал постуральной системы апломба, начинать целесообразно с феномена «тёмной комнаты», т.е. отсутствия света. Это может быть комната, кабинет или даже физкультурный зал с выключенным светом и плотными шторами на окнах. Именно здесь свой первый аккорд сделает вестибулярная система, а уже затем, чуть позже, при появлении визуальных ориентиров начнёт набирать функциональные обороты и зрительная система. Правильное чередование условных аккордов в развитии равновесия приведёт к гармонизации данной функции, а не к дисбалансу и разрушению необходимых координаций.

2. Метод «камертона». В этот «темный» период становления функции равновесия естественным образом актуализируется слуховая система, которая позволяет в значительной степени компенсировать отсутствие зрительных ориентиров при перемещениях в пространстве «тёмной комнаты». Даже коротко скрипнувшая в тёмной комнате входная дверь позволяет человеку гораздо лучше ориентироваться в пространстве и направиться в нужную сторону. Ухо ребёнка, словно музыкальный инструмент на камертон, начинает настраиваться на звуковой ряд внешнего мира. Данным методом предполагается усиление значения и использования звуковых ориентиров в пространстве специально создаваемой «тёмной комнаты». Здесь можно варьировать громкостью звука, его высотой, продолжительностью звучания, 
темпом, ритмом, гармонией, обращая особенное внимание на низкое акустическое звучание, являющееся естественным и очень значимым во внутриутробном периоде и периоде раннего онтогенеза ребёнка.

3. Метод «рассвета». И вот наконец долгожданный условный рассвет, когда темнота отступает под лучами пока ещё невидимого восходящего солнца и все предметы вокруг начинают обретать видимые, хорошо различаемые контуры. Именно в этой стадии, после родов новорождённый начинает включать и тренировать свою зрительную систему для ориентировки в пространстве, а, в дальнейшем, и сохранении равновесия при вертикализации головы, верхней части туловища, освоении функции сидения и т.д., вплоть до уверенного принятия полноценного ортоградного двухопорного положения. Визуализация внешнего пространства и объектов при данном подходе должна быть постепенной, переходя от эффекта «тёмной комнаты» к эффекту «залитой светом комнаты». На этом этапе для постуральной системы апломба практически полностью теряется значимость слуховой системы, несколько снижается актуальность вестибулярной (поскольку включились уже два канала управления равновесием, вестибулярный и зрительный), но зато начинают выстраиваться координационные взаимоотношения между вестибулярным аппаратом и зрением, что даёт системе постурального апломба уже первые преимущества звучания дуэта перед сольным исполнением каждого из инструментов этого условного оркестра.

Совершенствуя проприоцептивный канал постуральной системы апломба, можно взять за основу следующие методы развития равновесия у дошкольников:

1. Метод постепенного уменьшения площади опорной поверхности. В лежачегоризонтированных исходных положениях, при отсутствии вертикализации и ортоградных поз, площадь соприкосновения тела ребёнка с опорой является максимальной. Однако по мере вертикализации тела вплоть до двухопорного ортоградного положения площадь опоры постепенно снижается до минимума, который можно продемонстрировать на примере балерины, выполняющей танцевальный элемент «фуэтэ»: устойчивое вращение на пуанте одной стопы. В развитии функции равновесия можно взять за основу данный подход: начинать её тренинг с максимального мышечного ощущения соприкосновения с опорной поверхностью и далее следовать по пути постепенного уменьшения ощущения соприкосновения с опорой, сведя, в конце концов, её к минимальной.
2. Метод усиления проприоцептивных ощущений (метод «двух вееров»). Наблюдая за движениями канатоходца с шестом или исполнителя номера с веерами, стоящего на шаре, понимаешь, что при помощи этих дополнительных средств (шеста, вееров и др.) человек, выполняющий сложный трюк с сохранением равновесия, как бы искусственно усиливает свои проприоцептивные ощущения о своей позе в пространстве. При развитии и коррекции функции равновесия у детей дошкольного возраста можно использовать данный метод в адаптированном виде, используя в качестве усилителей проприоцептивных ощущений резиновые жгуты, стропы, TRS-петли, утяжелители, а также их сочетание. Особенно интересным может быть применение таких методических приёмов, как асимметричные утяжелители на конечностях, которые будут искажать проприоцептивное восприятие ребёнком истинного положения тела в пространстве. К перспективным направлениям реализации данного метода можно отнести также контрастный метод применения утяжелителей по типу «минимум - максимум», чтобы также искусственно сбивать проприоцептивные ощущения тела в пространстве и стимулировать более активное включение в работу системы равновесия других её каналов.

Для совершенствования подарного (подошвенного) постурального канала целесообразно использовать следующие методы:

1. «Топографический» метод. В процессе коррекции функции равновесия предполагается видоизменение, варьирование топографией опорной поверхности стоп по двум основным направлениям: от большей - к меньшей, а также различной по степени расположения опорной зоны в том или ином отделе стопы. Это может быть стояние на внутренних сводах стоп, на внешних, только на передних или на задних, на противоположных (левая стопа стоит на пятке, а правая - на носке; левая стопа опирается на внутренний свод, а правая - на внешний и т.д.). Такое топографическое варьирование даёт гораздо больше возможностей для подарного тренинга и стимулирования функции динамической устойчивости тела ребёнка на основе вариативного контактирования с опорой.

В этом плане определённый интерес может представлять метод, разработанный Н.Н. Ефименко и названный плантокоррекцией. Под плантокорректорами подразумеваются выполненные из линолеума или любого другого подобного материала следочки овальной формы размером 10 х 20 см, которые закрашены жёлтой краской определённым образом, например, только передние и внешние их зоны или, наоборот (при разворачивании на 180으), 
задние и внутренние зоны. Эти плантокорректоры раскладываются на поверхности опоры (пола) в определённом порядке для решения тех или иных задач подарной коррекции.

2. Метод «двухопорности - одноопорности». Совершенствуя функцию равновесия у детей с нарушениями опорно-двигательного аппарата, на первом этапе необходимо проводить тренинги в двухопорном ортоградном положении, т.е. с обязательным одновременным задействованием обеих стоп. На втором этапе развития (коррекции) динамической устойчивости у детей следует переходить к тренировкам в одноопорном положении, когда ребёнок будет контактировать с опорой только посредством одной стопы. Это должно в значительной степени повысить как сенсорные (подарные) возможности каждой стопы, так и их эффекторную результативность (способность реагировать на поступающие из мозга управленческие команды).

3. Метод сенсорной стимуляции. Для улучшения сенсорных (подарных) возможностей стоп имеет смысл систематично стимулировать подошвенную поверхность стоп детей при помощи различных по консистенции рельефных поверхностей: резиновых ковриков с рельефным рисунком, рыбацкой сети с узелками различного размера, пластиковых массажёров и т.д.

4. Контрастный метод. Данный метод развивает возможности предыдущего метода сенсорной стимуляции. Им предполагается целенаправленная контрастная стимуляция подошвенных поверхностей стоп при помощи опорных поверхностей противоположной фактуры: гладкая - шершавая, ровная - рельефная, выпуклая - вогнутая, с продольными массажными реками и поперечными, прохладная - тёплая и т.д.

5. Метод «ходуль». Можно отнести к парадоксальным методам, когда умышленно уменьшается площадь подарной опоры и делается стопная опора в 2 - 3 раза меньшей, чем она могла бы быть в естественных условиях прямостояния и прямохождения. Это заставляет активизироваться иные каналы постуральной системы апломба, например, проприоцептивный: захват руками ходуль и их плотное соприкосновение с туловищем обогащают проприоцептивные потоки, а высокое и неустойчивое положение на приподнятых ходулях активирует вестибулярную систему как составную часть глобальной системы динамической устойчивости тела в ортоградном положении.

Для совершенсования окуломоторного сенсорного канала постуральной системы апломба можно использовать следующие методы:

1. Метод расширения окуломоторных пространственно-временных возможностей глаз.
При данном подходе предусматривается использование специальных упражнений для мышц глаз, управляющих движениями глазного яблока. Предполагается увеличение амплитуды движений глазным яблоком во всех плоскостях, скорости перемещения глазного яблока, частоты движений веками и собственно глазным яблоком, бинокулярной составляющей зрительной системы.

Здесь за основу можно взять уже существующие разработки М.С. Норбекова, в частности его гимнастику для глаз [5], и усилить, усложнить её введением стабильного или подвижного предмета как цели для наблюдения за ним. В этом плане интересными также представляются разработки В.Ф. Базарного [2] для профилактики возникновения ученической миопии и для расслабления мышц глаз во время школьных уроков, в основе которых лежит прослеживание взглядом за нарисованными на потолке и стенах линиями, и другие интересные упражнения.

2. Метод «мячика». Продолжая идею предыдущего метода отслеживания какого-либо предмета в окружающем пространстве, можно прийти к идее зрительного и окуломоторного взаимодействия с мячами различного размера, цвета, прыгучести и консистенции. С помощью данного подхода можно тренировать быстроту реакций окуломоторного аппарата ребёнка на быстродвижущийся объект, каковым в идеале является мячик, используемый в различных играх. Это может быть теннисный мячик (используемый в большом теннисе), шарик от настольного тенниса, каучуковый мячик-попрыгунчик и другие.

Можно также взять на заметку элементы подготовки стрелков по движущейся мишени или тарелкам.

3. Метод избирательного визуального захвата объекта. Данным методом можно развивать и корригировать способность ребёнка выхватывать визуально из множества объектов единственный, самый значимый в данной двигательноигровой ситуации объект для получения необходимых координат положения тела в пространстве и стабилизирующей составляющей окуломоторного канала постуральной системы апломба.

Эти методические подходы можно найти в огневой подготовке бойцов спецназа, которых обучают молниеносно визуально анализировать ситуацию, выделять главный объект для поражения и произведение по нему выстрела, что является главным условием выживания в бою. Естественно, что эти методики должны быть адаптированы к психофизическим особенностям детей дошкольного возраста.

Подводя итоги статьи, можно сделать следующие предварительные выводы: 
1. Обзор имеющихся по данной проблеме литературных источников выявил фрагментарность предлагаемых методов, отсутствие их систематизации применительно к развитию функции равновесия у детей дошкольного возраста с нарушениями опорно-двигательного аппарата.

2. В статье была предпринята попытка такой систематизации существующих методов развития и коррекции функции равновесия у данной категории детей на основе совершенствования всех пяти внешних и внутренних каналов постуральной системы апломба.

К перспективам исследования методов развития и коррекции функции равновесия у дошкольников с двигательными нарушениями относится разработка конкретных комплексов упражнений по каждому из разрабатываемых методов с дальнейшей их практической апробацией на данном контингенте детей.

\section{Списокиспользованныхисточников}

1. Гаже П.-М., Вебер Б. Постурология. Регуляция и нарушения равновесия тела человека / П.М.Гаже, Б. Вебер и др. : пер. с франц. Под ред. В.И.Усачёва. - СПб. : Издательский дом СПбМАПО, 2008. - 316 с., ил.

2. Базарный В.Ф. Дитя человеческое: психофизиология развития и регресса / В. Ф. Базарный. - М. : Пульс, 2015. - 432 с.

3. Барановская Е.Н. Формирование установочных поз и ходьбы у детей дошкольного и младшего школьного возраста с детским церебральным параличом : дис. канд. педаг. наук : 13.00 .04 / Е.Н. Барановская. [Место защиты: Федер. науч. центр физической культуры и спорта]. - Москва, 2013. - 181 с. : ил.

4. Гурулёва Т. Г. Воспитание координационных способностей в спортивно-оздоровительных группах детей 6 - 7 лет : дис. канд. пед. наук : 13.00 .04 / Т. Г. Гурулёва. - Улан-Удэ, 2006. - 150 с.

5. Норбеков М. С. Опыт дурака или ключ к прозрению / М. С. Норбеков. - 2-е изд., исправ. - М. : Астрель, 2012. - 259 с.

6. Руденко С.А. Развитие способности к равновесию у детей 6 - 7 лет : дис. канд. пед. наук : 13.00.04. - Санкт-Петербург, 1999. - 247 с. : ил.

7. Уханева Е. В. Организация физического воспитания детей раннего возраста на основе развития функции равновесия : дис. канд. пед. наук : 13.00.04 / Е.В. Уханева. - Санкт-Петербург, 2002. - 172 с.

\section{References}

1. Gaje P.-M. (2008) Postýrologıla. Regýlıatsıla ı narýshenıla ravnovesıla tela cheloveka [Postology. Regulation and imbalance of the human body] SPb. : Izdatelskı dom SPbMAPO [in Russian].

2. Bazarnыi V.F. (2015) Dytia chelovecheskoe: psykhofyzyolohyia razvytyia y rehressa [Human child: the psychophysiology of development and regression] M. : Puls,. - 432 s. [in Russian].

3. Baranovskaia E.N. (2013) Formyrovanye ustanovochnыkh poz y khodbы u detei doshkolnoho y mladsheho shkolnoho vozrasta s detskym tserebralnum paralychom: dys. [Formed installation poses and moves in children of preschool and primary school age with cerebral palsy ] kand. ped. nauk : 13.00 .04 / - 181 s. : yl. [in Russian].

4. Hurulëva T.H. (2006) Vospytanye koordynatsyonnыkh sposobnostei v sportyvno-ozdorovytelnukh hruppakh detei 6 - 7 let [Educated coordination abilities in sports and fitness groups of children 6-7 years old]: dys. kand. ped. nauk : 13.00 .04 / Ulan-Udэ, - 150 s. : yl. [in Russian].

5. Norbekov M. S. (2012) Opыt duraka yly kliuch k prozrenyiu [Fool experience or the key to enlightenment] M. : Astrel,. - 259 s. [in Russian].

6. Rudenko S.A. (1999) Razvytye sposobnosty k ravnovesyiu u detei 6- 7 let [Developmental balance abilities in children 6-7 years old] : dys. kand. ped. nauk : 13.00 .04 / - S.- Pb, - 247 s. : yl. [in Russian].

7. Ukhanëva E.V. (2002) Orhanyzatsyia fyzycheskoho vospytanyia detei ranneho vozrasta na osnove razvytyia funktsyy ravnovesyia [Organization of physical education for younger children based on the development of equality functions]: dys. kand. ped. nauk : 13.00.04. / - S.-Pb,. - 172 s. [in Russian].

\section{Бочков Павло. Методи розвитку і корекції рівноваги у дошкільнят}

у статті систематизовано та проаналізовано методи формування функції рівноваги у дошкільнят з порушеннями опорно-рухового апарату. В основу корекції динамічної стійкості у даного контингенту дітей були покладені філогенетично зумовлені механізми постуральної системи апломбу, відбиті в періоди раннього онтогенезу дитини: вестибулярна - зорова - проприоцептивна - подарна - окуломоторна. Для вдосконалення кожного з цих вхідних каналів постуральної системи апломбу був розроблений специфічний методичний алгоритм розвитку і корекції функції рівноваги у дошкільнят з моторними порушеннями. Для вестибулярного каналу пропонується використовувати методи гідравлічної перевернутої (дзеркальності), «невагомості», плавності (дозованих кутових прискорень). Для зорового каналу можна використовувати методи «темної кімнати», «камертона», «світанку». Удосконалення проприоцептивного каналу постуральної системи апломбу передбачає застосування методів поступового зменшення площі опорної поверхні, посилення пропріоцептивних відчуттів (метод «двох віял»). Подарний канал вестибулярної системи дитини можна розвивати за допомогою таких методів: «топографічного», «двухопорного - одноопорного», сенсорної стимуляції, контрастного методу, а також методу «ходуль». Окуломоторика дитини з порушеннями рівноваги може бути вдосконалена за допомогою метода розширення окуломоторних просторово-часових можливостей очей, методу “м'ячика», а також методу візуального виборчого захоплення об'єкта, виокремлення його з безлічі об'єктів або швидкоплинні обстановки. Дана класифікація методів з їх умовним поділом на природні, філогенетичні і онтогенетичні зумовлені, і штучні, засновані на застосуванні предметно-просторової складової 
(обладнання, тренажерів та інвентарю), а також використовують можливості інформаційнокомп'ютерних технологій з зворотньо біологічним зв'язком.

До перспектив дослідження методів розвитку і корекції функції рівноваги у дошкільнят з руховими порушеннями відноситься розробка конкретних комплексів вправ по кожному з розроблюваних методів з подальшою їх практичною апробацією на даному контингенті дітей.

Ключові слова: методи, рівновага, дошкільнята, рухові порушення, постуральна система апломбу.

\section{Bochkov Pavel Balance state development and correction methods in preschool children}

In the article the methods of balance function formation in preschool children with musculoskeletal system disorders are systematized and analyzed. In the basis of dynamic stability correction in this children contingent were laid phylogenetically predisposed mechanisms of the postural aplomb system, reflected in periods of early child ontogeny: vestibular - visual - proprioceptive - gift - oculomotor. To improve each of these input channels of the aplomb postural system, a specific technique algorithm for the development and correction of the balance function in preschool children with motor disorders was developed. For the vestibular channel it is suggested to use methods of hydraulic inverted (mirroring), "weightlessness", smoothness (metered angular accelerations). For the visual channel you can use the methods of "dark room", "tuning fork", "dawn". Proprioceptive channel improvement of the postural aplomb system involves the use of gradually reducing methods of bearing surface area, strengthening proprioceptive sensations (the method of "two fans"). The given canal of the child vestibular system can be developed using such methods as "topographic", "two-axis - one-axis", sensory stimulation, contrast method, and also the method of "stilts". The oculomotor system of child with balance state disturbances can be improved by the method of expanding oculomotor space-time eyes possibilities, the method of the ball, as well as the method of visual selective object capture, separating it from a variety of objects or from fleeting environment. This classification of methods are given with their conditional division into natural, phylogenetic and ontogenetic predetermined, and artificial, based on the use of the subject-spatial component (equipment, simulators and inventory), as well as the use of the possibilities of information and computer technologies with reverse biological bonds.

The prospects of studying the development methods and correction of balance function in preschool children with motor disorders is the development of specific exercise complexes for each of the developed methods, followed by their practical testing in this children contingent.

Key words: methods, balance, preschool children, motor disorders, postural aplomb system. 